Article

\title{
Antioxidant and Photoprotective Effects of Blanch Water, a Byproduct of the Almond Processing Industry
}

\author{
Giuseppina Mandalari ${ }^{1,2}$, Teresita Arcoraci ${ }^{1}$, Maria Martorana ${ }^{1}$, Carlo Bisignano ${ }^{3}$, \\ Luisa Rizza ${ }^{4}$, Francesco Paolo Bonina ${ }^{4}$, Domenico Trombetta ${ }^{1}$ and Antonio Tomaino ${ }^{1, *}$ \\ 1 Dipartimento di Scienze del Farmaco e dei Prodotti per la Salute, University of Messina, \\ Viale Annunziata, Messina 98100, Italy \\ 2 Model Gut Platform, Institute of Food Research, Norwich Research Park, Colney Lane NR4 7UA, \\ Norwich, UK \\ 3 Dipartimento di Scienze Biologiche ed Ambientali, University of Messina, Sal. Sperone, \\ Messina 98100, Italy \\ 4 Dipartimento of Pharmaceutical Science, Faculty of Pharmacy, University of Catania, \\ Viale Andrea Doria, Catania 95125, Italy \\ * Author to whom correspondence should be addressed; E-Mail: atomaino@unime.it; \\ Tel.: +39-90-676-6577.
}

Received: 28 August 2013; in revised form: 26 September 2013 / Accepted: 27 September 2013 / Published: 9 October 2013

\begin{abstract}
The aim of the present work was to evaluate the antioxidant and photoprotective effect of blanch water (BW), a byproduct of the almond processing industry. The polyphenolic content of a BW extract, the level of proanthocyanidins and the vanillin index determination were determined. The antioxidant activity and the radical scavenging activity of the BW were evaluated by a range of in vitro tests. The in vivo photoprotective effect was investigated using a formulation containing $2 \%$ of the BW extract on skin erythema induced by acute UV-B exposure in twelve volunteers. Results confirmed the presence of added-value antioxidant compounds in the industrial BW extract, and the most representative compounds were naringenin-7-O-glucoside and kaempferol-7-O-rutinoside. The proanthocyanidin content was $71.84 \pm 5.21$ cyanidin equivalents/g of BW extract. The good antiradical activity of the BW extract was demonstrated in both the DPPH ${ }^{*}$ test and in the Reducing Power test. The percentage inhibition of erythema obtained using a formulation of BW was 50.48, value clearly demonstrating an effect against photooxidative damage in vivo.
\end{abstract}


Keywords: blanch water; byproduct; photoprotective; antioxidant; polyphenols

\section{Introduction}

In recent human studies, almond consumption was shown to have beneficial effects on blood glucose levels in individuals with type-2 diabetes and prediabetes, with statistically-significant improvements in fasting levels of glucose, insulin, insulin sensitivity and LDL-cholesterol [1,2]. Evidence from observational reports have also indicated that phytochemicals may be related to the beneficial effects associated with almond consumption, reducing the risk of several chronic conditions and certain forms of cancer [3,4]. A number of studies have reported on the distribution of flavonoids and phenolics in almond skins [5,6]. Almond skin is recognised as a useful ingredient for the control of oxidative processes in food products and as a functional food ingredient in its own right. We have previously identified the flavonoids (flavanols, flavonols and flavanones) and phenolic acids present in almond skins and demonstrated that they are bioaccessible in the upper gastrointestinal (GI) tract and therefore potentially available for absorption during digestion [5,7]. The most represented flavonoids present in almond skins are (+)-catechin, ( )-epicatechin, kaempferol, and isorhamnetin, the latter as 3-O-rutinoside or 3-O-glucoside [5]. Blanched almond skins, industrially removed from the nut by hot water blanching, constitute $4-8 \%$ of the total shelled almond weight and are considered byproducts, which if not processed further, are discarded as waste. As expected, blanching results in a substantial loss of polyphenols and antioxidant activity to the blanch water [5,6]. The almond processing industries are interested in the valorisation of these byproducts which at present are mainly used in cattle feed [8] and in gasification plants to produce energy [9].

The protective effect of plant polyphenols from damage produced by reactive oxygen species (ROS) including exposure to ultraviolet (UV) radiation has been previously reported [10,11]. A range of natural compounds has been investigated for their photoprotective effect, exerted both when ingested through the diet and if topically applied [12,13].

The aims of the present work were to investigate the antioxidant properties of an industrial extract of almond blanch water (BW) and evaluate its potential use in topical photoprotective formulation to improve skin health. On the basis of the in vitro antioxidant data, a topical formulation containing BW extract was tested in vivo for its ability to reduce UV-B-induced skin erythema. This test is considered the most representative model to investigate skin damage in vivo post-acute UV-exposure $[14,15]$.

\section{Results and Discussion}

\subsection{Polyphenolic Content in Blanch Water}

Table 1 shows the polyphenolic content in BW, expressed as $\mu \mathrm{g} / \mathrm{g}$ extract of phenolic acids, flavan-3-ols, flavanones and flavonols. As previously reported [5], the most representative compounds identified were naringenin-7-O-glucoside and kaempferol-7- $O$-rutinoside, followed by catechin and 5-hydroxybenzoic acid. Neither quercetin nor kaempferol were found in BW, mainly due to their poor water solubility. 
Table 1. Quantitative analysis of phenolics in the BW extract. Results are expressed as mean \pm SD of three independent samples.

\begin{tabular}{cc}
\hline Phenol & BW $(\boldsymbol{\mu g} / \mathbf{g}$ extract $)$ \\
\hline Phenolic acids & $778.71 \pm 65.35$ \\
Protocatechuic acid & $73.19 \pm 6.35$ \\
$p$-Hydroxybenzoic acid & $542.37 \pm 45.81$ \\
Chlorogenic acid & $84.32 \pm 7.64$ \\
Vanillic acid & $63.54 \pm 4.51$ \\
trans $p$-Coumaric acid & $15.29 \pm 1.04$ \\
Flavan-3-ols & $1069.50 \pm 79.67$ \\
Aglycones & $1069.50 \pm 79.67$ \\
Catechin & $693.41 \pm 51.49$ \\
Epicatechin & $376.09 \pm 28.18$ \\
Flavanones & $842.65 \pm 82.94$ \\
Aglycones & $69.99 \pm 5.64$ \\
Eriodictyol & $16.27 \pm 1.24$ \\
Naringenin & $53.72 \pm 4.40$ \\
Glycosides & $820.23 \pm 77.30$ \\
Eriodictyol-7- $O$-glucoside & $4.85 \pm 2.71$ \\
Naringenin-7- $O$-glucoside & $815.38 \pm 74.59$ \\
Flavonols & $1089.54 \pm 89.81$ \\
Glycosides & $1089.54 \pm 89.81$ \\
Quercetin-3- $O$-rutinoside & $79.43 \pm 6.21$ \\
Quercetin-3- $O$-glucoside & $7.13 \pm 0.62$ \\
Kaempferol-3- $O$-rutinoside & $803.54 \pm 65.03$ \\
Kaempferol-3- $O$-glucoside & $33.73 \pm 2.76$ \\
Isoramnetin-3- $O$-rutinoside & $42.12 \pm 3.57$ \\
Isoramnetin-3- $O$-glucoside & $123.59 \pm 11.62$ \\
\hline
\end{tabular}

Although a similar qualitative profile has been reported by other authors [6], it is not possible to make meaningful comparisons due to differences in variety, year of production, environmental conditions and extraction methods [16]. Furthermore, Milbury et al. [6] designed experimental blanching conditions mimicking industrial processing, whereas the BW used in the current study was industrially produced. These data confirmed the presence of added-value antioxidant compounds in the industrial BW extract, which may be used as dietary antioxidant ingredients.

Proanthocyanidins have been reported to possess a broad spectrum of biological, pharmacological and therapeutic properties related to their radical scavenging and antioxidant activities [17-19]. In particular, the presence of one or more catechol moieties in their structure seems to be a key factor in determining the scavenging activity. In our study, the content of proanthocyanidins in BW extract was $71.84 \pm 5.21 \mathrm{CyE} / \mathrm{g}$ of extract (Table 2). The vanillin index provides an estimate of the number of C-6 and C-8 free of both catechins and proanthocyanidins. Proanthocyanidins are slightly less reactive than the catechins only when at least one of the two sites, C-6 and C-8, is free. This index decreases with the increase in polymerization degree, because many of the C- 6 and C- 8 positions are involved in the polymerization step. We measured a vanillin index of $29.45 \pm 2.69 \mathrm{mg}$ of catechin equivalents/g of 
BW extract. The polymerization index is the result of the vanillin assay divided by the proanthocyanidin assay; this ratio provides a rough estimate of the degree of polymerization of the flavonols. The low value (0.41) of polymerization index in the BW extract calculated in the present work indicates that the BW extract has large amount of polymeric tannins. Our results are different compared to the values reported by Pérez-Jiménez and Lluís Torres [20], possibly because the BW extract used in the current work, which was not submitted to any extraction process with organic solvent, did not contain extractable proanthocyanidins.

Table 2. Content of proanthocyanidins, flavanols reactive to vanillin (vanillin index) and polymerization index determined in the blanch water (BW) extract. Results are expressed as mean $\pm \mathrm{SD}$ of three independent determinations.

\begin{tabular}{cc}
\hline Component & BW \\
\hline $\begin{array}{cc}\text { Proanthocyanidins } \\
m g C y E / g \text { extract }{ }^{a}\end{array}$ & $71.84 \pm 5.21$ \\
Vanillin index & $29.45 \pm 2.69$ \\
$m g$ CatE $/ g$ extract ${ }^{b}$ & 0.41 \\
${ }^{\text {a }}$ CyE: Cyanidin chloride Equivalents; ${ }^{\mathrm{b}}$ CatE: Catechin Equivalents.
\end{tabular}

\subsection{Antioxidant Activity of Blanch Water}

The antioxidant and radical scavenging properties of the polyphenolic compounds present in BW has been demonstrated using a range of tests (Table 3 ).

Table 3. Antioxidant activity of the blanch water (BW) extract measured by means of different in vitro tests. Data are expressed as mean $\pm \mathrm{SD}$ of three independent experiments.

\begin{tabular}{ccc}
\hline Assay & Unit & BW \\
\hline Folin-Ciocalteau test & $\mathrm{mg} \mathrm{GAE} / \mathrm{g}$ & $90.28 \pm 5.47$ \\
DPPH test & ${ }^{\mathrm{a}} \mathrm{SE}_{50}(\mu \mathrm{g})$ & $132.82 \pm 12.02$ \\
Reducing Power test & ${ }^{\mathrm{b}} \mathrm{mmoles} \mathrm{AAE} / \mathrm{g}$ & $2.02 \pm 0.11$ \\
$\beta$-Carotene blanching test & ${ }^{\mathrm{c}} \mathrm{IC}_{50}(\mu \mathrm{g} / \mathrm{mL})$ & $232.86 \pm 21.45$ \\
UV-IP test & ${ }^{\mathrm{d}} \mathrm{IC}_{50}(\mu \mathrm{g} / \mathrm{mL})$ & $531.11 \pm 44.91$ \\
\hline
\end{tabular}

${ }^{\mathrm{a}} \mathrm{mg}$ of blanch water extract needed to scavenge 50 mmoles of DPPH. ${ }^{\mathrm{b}}$ mmoles of ascorbic acid equivalent/g of extract. ${ }^{\mathrm{c}} \mathrm{mg} / \mathrm{mL}$ of extract needed to inhibit by $50 \% \beta$-carotene bleaching. ${ }^{\mathrm{d}} \mathrm{mg} / \mathrm{mL}$ of extract needed to inhibit by $50 \%$ MDA production.

The total phenolic content expressed as mg of gallic acid equivalents (GAE) per $\mathrm{g}$ of BW extract was $90.28 \pm 5.47$. This value is directly comparable with our previous investigation [5] and significantly lower than the values reported by Milbury et al. [6], who found between $50.3 \mathrm{mg}$ GAE and $153.9 \mathrm{mg}$ GAE from blanching $100 \mathrm{~g}$ of fresh natural almonds. The good antiradical activity of the BW extract showed in the DPPH test (expressed as $\mathrm{SE}_{50}$, amount needed to scavenge $50 \mu$ moles of the initial $\mathrm{DPPH} \cdot$ solution) and in the Reducing Power test (expressed as mmoles ascorbic acid equivalents per $\mathrm{g}$ 
of BW extract) confirmed the higher antioxidant capacity in vitro of almond polyphenols compared to vitamins and carotenoids [21].

Both the Folin-Ciocalteau method and the Reducing Power test are electron/transfer based assays, performed in alkaline and acid conditions, respectively. The acidic $\mathrm{pH}$ may reduce the activity of phenolic antioxidants in vitro due to protonation, whereas the alkaline $\mathrm{pH}$ could enhance the antioxidant potential due to dissociation [22]. Therefore, a range of tests is always warranted to evaluate the antioxidant potential of polyphenolic compounds in vitro. The activity found in the BW extract by the Folin-Ciocalteau method and the Reducing Power test was higher compared to pistachio seeds and lower than the values obtained with pistachio skin [11]. The results obtained with the $\beta$-carotene bleaching test and the UV-IP test confirmed that the antioxidant compounds present in BW were able to protect from lipid peroxidation induced by heating or UV-C light.

\subsection{In Vivo Photoprotective Effect of Blanch Water}

On the basis of the in vitro antioxidant data, the BW extract was used as topical photoprotective agent in human volunteers suffering from skin erythema induced by acute UV-B exposure. Figure 1 shows the typical trend of erythema index variations ( $\triangle \mathrm{EI})$ versus time for one subject when applying a formulation containing either the BW extract ( $2 \%$ ) or tocopheryl acetate (TOC, $2 \%)$.

Figure 1. Typical trend of erythema index variations ( $\Delta \mathrm{EI})$ versus time for one subject. Formulations containing $2 \%$ of the active ingredients under study (blanch water extract, $\mathrm{BW}$, or tocopheryl acetate, TOC) or containing no active ingredient (blank) were applied to the skin after UV-B exposure. No treated skin sites were used as control.

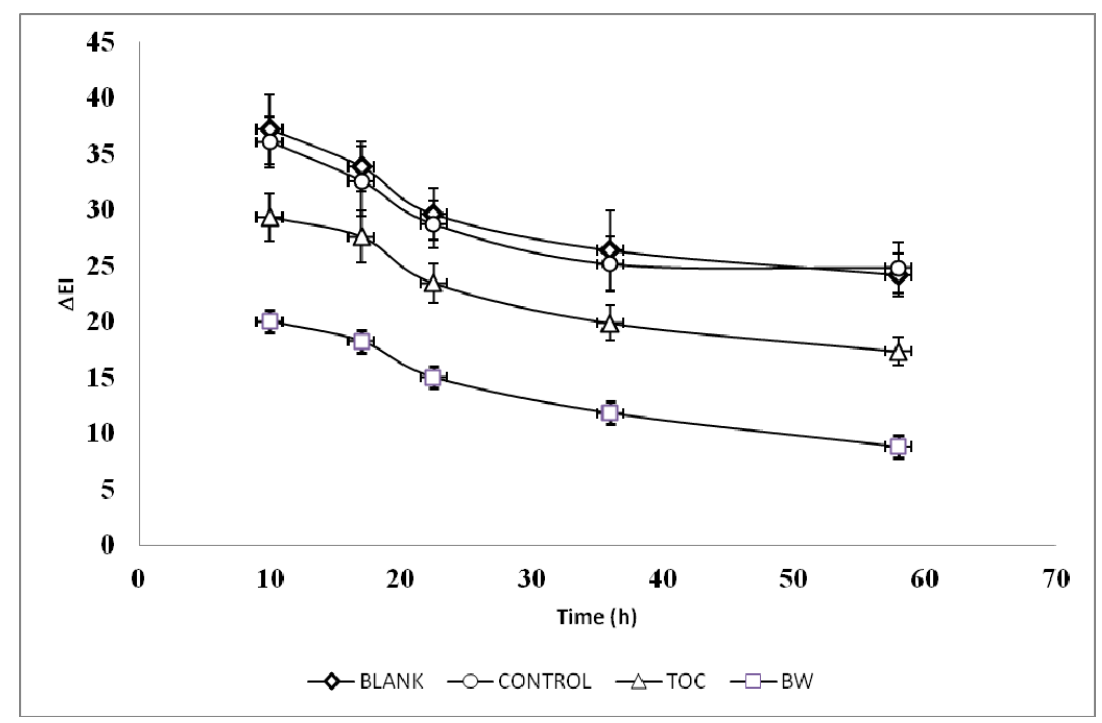

Both active ingredients were able to better protect the skin against UV-B erythema compared to the blank formulation and the control skin site. The $\mathrm{AUC}_{0-58}$ values, which refer to the change of the UV-B erythema over time for each volunteer, were slightly lower with TOC formulation compared to the BW extract $(p<0.05)$ (Table 4). These data are well comparable with the results obtained using an extract of pistachio seed and pistachio skin, demonstrating the potential beneficial effect of nut polyphenols on skin health [11]. Other plant extracts have successfully been tested as photoprotective 
agents $[13,15,23-29]$ and their skin healthy effects have been attributed to the high content of phenolic compounds.

Table 4. $\mathrm{AUC}_{0-58}$ values obtained by applying either the blanch water extract $(\mathrm{BW})$, tocopheryl acetate (TOC) or blank formulations to UV-B-exposed skin sites. Data are expressed as mean \pm SD and analyzed by Student's t test for unpaired data.

\begin{tabular}{|c|c|c|c|c|}
\hline Subject & Control & Blank & TOC & BW \\
\hline A & $1383.27 \pm 120.59$ & $1365.41 \pm 115.67$ & $1126.38 \pm 66.12$ & $654.68 \pm 50.67$ \\
\hline B & $1522.18 \pm 102.40$ & $1356.08 \pm 100.09$ & $954.23 \pm 73.64$ & $700.36 \pm 55.24$ \\
\hline $\mathrm{C}$ & $1125.35 \pm 97.97$ & $1296.34 \pm 95.67$ & $1115.45 \pm 69.58$ & $765.68 \pm 49.29$ \\
\hline $\mathrm{D}$ & $1248.05 \pm 120.26$ & $1456.44 \pm 134.25$ & $1048.11 \pm 75.15$ & $643.28 \pm 50.71$ \\
\hline $\mathrm{E}$ & $1392.61 \pm 124.65$ & $1108.87 \pm 87.43$ & $1084.65 \pm 79.26$ & $696.03 \pm 45.38$ \\
\hline $\mathrm{F}$ & $1275.87 \pm 100.65$ & $1284.60 \pm 102.58$ & $1035.44 \pm 65.37$ & $624.95 \pm 47.08$ \\
\hline G & $1396.14 \pm 115.38$ & $1326.94 \pm 118.05$ & $973.12 \pm 70.25$ & $644.76 \pm 56.16$ \\
\hline $\mathrm{H}$ & $1471.85 \pm 121.37$ & $1285.67 \pm 112.82$ & $1219.12 \pm 76.41$ & $545.84 \pm 39.88$ \\
\hline I & $1329.53 \pm 104.41$ & $1574.24 \pm 136.57$ & $1065.21 \pm 81.36$ & $712.59 \pm 42.79$ \\
\hline $\mathrm{L}$ & $1507.39 \pm 99.37$ & $1429.41 \pm 126.48$ & $941.72 \pm 62.74$ & $907.33 \pm 57.29$ \\
\hline M & $1436.27 \pm 124.84$ & $1230.50 \pm 95.66$ & $1119.35 \pm 80.54$ & $650.82 \pm 45.44$ \\
\hline $\mathrm{N}$ & $1284.08 \pm 104.73$ & $1236.77 \pm 122.5$ & $1023.68 \pm 68.25$ & $560.61 \pm 48.36$ \\
\hline mean & 1364.38 & 1329.27 & 1058.87 & 675.57 \\
\hline \pm S.D. & 116.93 & 120.64 & 80.75 & 95.29 \\
\hline PIE (\%) & $-\ldots$ & $-\ldots$ & $22.39^{\mathrm{a}}$ & $50.48^{\mathrm{a}, \mathrm{b}}$ \\
\hline
\end{tabular}

The percentage inhibition of erythema (PIE) values obtained using formulations of either BW or TOC were 50.48 and 22.39, respectively (Figure 2). These results clearly demonstrated an effect of BW against photooxidative damage in vivo.

Figure 2. Percentage inhibition of erythema (PIE) values obtained after skin application of formulations containing either the blanch water extract (BW, 2\%) or tocopheryl acetate (TOC, $2 \%$ ), calculated $v s$. blank samples.

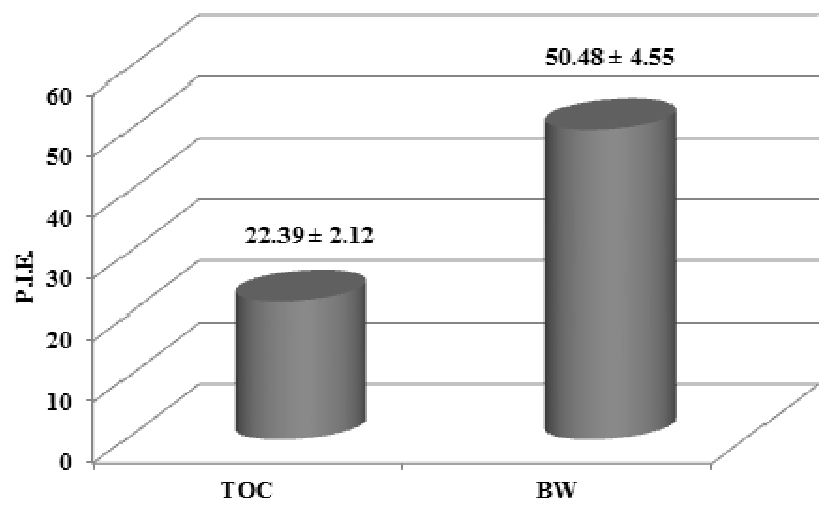




\section{Experimental}

\subsection{Preparation of the Blanch Water (BW) Extract}

BW, after thawing, was brought to room temperature and maintained under continuous stirring. An aliquot $(20 \mathrm{~mL})$ was centrifuged at 4,200 $\times \mathrm{g}$ for $5 \mathrm{~min}$ (Minifuge 2; Heraeus-Christ, Osterode, Germany), the supernatant was dried by a rotary evaporator (R-205; Büchi, Flawil, Switzerland) and the obtained residue $(73.10 \mathrm{mg})$ was stored at $-20{ }^{\circ} \mathrm{C}$ until further use. For all experiments, the BW extract was dissolved in the minimum volume of a mixture methanol (purity $\geq 99.9 \%$; Carlo Erba, Milan, Italy)/water (2/1).

\subsection{HPLC Analysis of Phenolics and Flavonoids}

The qualitative/quantitative determination of phenolics and flavonoids in BW was carried out using a Shimadzu high performance liquid chromatography system equipped with a UV-vis photodiode-array detector (DAD, SPD-M10Avp) and a fluorescence detector (1046A; Hewlett Packard). The apparatus was controlled by a control system (SCL-10Avp) equipped with an LC pump (LC-10 ADvp) and an auto-injector (SIL-10ADvp). The chromatographic separation was obtained by a $5 \mathrm{~mm}$ ODS3 reversed-phase Prodigy column $(250 \mathrm{~mm} \times 4.6 \mathrm{~mm}$; Phenomenex, Inc., Torrance, CA, USA) with solvent A (water/acetic acid (HPLC grade, purity $\geq 99.5 \%$; Rudi Pont, Carlo Erba, Italy), 98/2, v/v), solvent B (water/acetonitrile (HPLC PLUS grade, purity $\geq 99.9 \%$; Carlo Erba)/acetic acid, $73 / 25 / 2, \mathrm{v} / \mathrm{v} / \mathrm{v}$ ) and solvent $\mathrm{C}$ (acetonitrile) as mobile phase [3]. The gradient program started with $100 \% \mathrm{~A}$ to reach $20 \% \mathrm{~A}$ and $80 \% \mathrm{~B}$ at $55 \mathrm{~min}, 10 \% \mathrm{~A}$ and $90 \% \mathrm{~B}$ at $57 \mathrm{~min}, 100 \% \mathrm{~B}$ at $90 \mathrm{~min}$ and $100 \% \mathrm{C}$ at $105 \mathrm{~min}$. The flow rate was $1 \mathrm{~mL} / \mathrm{min}$, and the column was thermostatically controlled at $25^{\circ} \mathrm{C}$. The extract was filtered through a $0.2 \mu \mathrm{m}$ filter (nylon; Millipore Corporation, Milford, MA, USA) and the injection volume was $75 \mu \mathrm{L}$. All analyses were carried out in triplicate. Identification of compounds was carried out by comparing their spectra and retention times with those of external standards. Detection was performed at $270 \mathrm{~nm}$ for hydroxybenzoic acids and flavanones and at $370 \mathrm{~nm}$ for flavonols. The UV spectra of the different compounds were recorded from 240 to $400 \mathrm{~nm}$. The wavelengths used for fluorescence detection of flavan-3-ols were: $\lambda_{\mathrm{ex}}: 276 \mathrm{~nm}, \lambda_{\mathrm{em}}: 316 \mathrm{~nm}$. Data acquisition was performed using Class-VP5 Chemstation software (Shimadzu, Kyoto, Japan). All flavonoid and other phytochemical standards (flavanones glycosides and aglycones, flavone glycosides, phenolic acids) were obtained either from Sigma-Aldrich (Poole, UK) or Extrasynthese (Genay, France).

\subsection{Levels of Proanthocyanidins}

The method used for determining the content of proanthocyanidins is based on their transformation into anthocyanidins, leading to a shift of colour towards the red zone in a warm and acid environment [26]. An aliquot (50 mg) of the extract, diluted (approximately 10-20 times) with $0.05 \mathrm{M} \mathrm{H}_{2} \mathrm{SO}_{4}$, was loaded onto a conditioned Sep-Pak $\mathrm{C}_{18}$ (Waters, Milford, MA, USA), which was washed with $2 \mathrm{~mL}$ of $5 \mathrm{mM}$ $\mathrm{H}_{2} \mathrm{SO}_{4}$ and purged with air. The fraction rich in proanthocyanidins was eluted with $3 \mathrm{~mL}$ of $\mathrm{MeOH}$ and collected into a $50 \mathrm{~mL}$ flask shielded from light (aluminium foil) and containing $9.5 \mathrm{~mL}$ absolute EtOH. The mixture was added with $12.5 \mathrm{~mL}$ of $\mathrm{FeSO}_{4} \cdot 7 \mathrm{H}_{2} \mathrm{O}$ in concentrated $\mathrm{HCl}(300 \mathrm{mg} / \mathrm{L})$ and the 
flask was then placed in a boiling water bath and refluxed for $50 \mathrm{~min}$, after which it was rapidly cooled by immersion in cold water $\left(20^{\circ} \mathrm{C}\right)$. After $10 \mathrm{~min}$, the absorbance at $550 \mathrm{~nm}$ was registered on a UV-Visible spectrophotometer (UV-1601 UV-visible; Shimadzu). To account for the basal content of anthocyanins present in the sample, the corresponding absorbance value of each extract prepared under the same conditions, but cooled in ice and not warmed, was subtracted to obtain the net absorbance value. Under such conditions, the average yield was $20 \%$ and the proanthocyanidin concentration can be conventionally expressed as 5 times the amount of cyanidin formed, by means of a calibration curve with cyanidin chloride ( $\varepsilon=34,700$ according to Di Stefano, Cravero, and Gentilini [30]). Each determination was performed in triplicate.

\subsection{Vanillin Index Determination}

The concentration of polyphenols reactive to vanillin in a highly acid environment was determined according to the method described by Margheri and Falcieri and by Tomaino et al. [31,32]. Vanillin is a relatively stable aldehyde at high $\mathrm{H}_{2} \mathrm{SO}_{4}$ concentrations; it reacts with free carbons $\mathrm{C} 6$ and $\mathrm{C} 8$ of flavan-3-ols, leading to the formation of a red complex with maximum absorbance at $500 \mathrm{~nm}$. Briefly, $2 \mathrm{~mL}$ of the extract, diluted with $0.5 \mathrm{M} \mathrm{H}_{2} \mathrm{SO}_{4}$ to obtain a final reading between 0.2 and $0.4 \mathrm{AU}$, were loaded onto a conditioned Sep-Pak $\mathrm{C}_{18}$ (Waters Corporation). The column was washed with $2 \mathrm{~mL}$ of $5 \mathrm{mM} \mathrm{H}_{2} \mathrm{SO}_{4}$, purged with air and eluted with $5 \mathrm{~mL}$ of $\mathrm{MeOH}$ into a test tube. One milliliter of the methanolic eluate was placed in a test tube (shielded from light), together with $6 \mathrm{~mL}$ of $4 \%$ vanillin in $\mathrm{MeOH}$ and immersed in a water bath at $20^{\circ} \mathrm{C}$ for $10 \mathrm{~min}$. After cooling, $3 \mathrm{~mL}$ of concentrated $\mathrm{HCl}$ were added. After $15 \mathrm{~min}$, the absorbance of the pigment was read on a Shimadzu UV-1601 UV-visible spectrophotometer at $500 \mathrm{~nm}$ against a blank prepared under the same conditions and containing only $\mathrm{MeOH}$. Results were expressed as mg of CatE for $\mathrm{g}$ of extract. Each determination was performed in triplicate.

\subsection{Evaluation of Antioxidant Activity}

\subsubsection{Folin-Ciocalteau Method}

The antioxidant capacity of the BW extract was determined by the Folin-Ciocalteau reagent [29]. Total phenol content was expressed as $\mathrm{mg}$ of gallic acid equivalents (GAE)/g of extract. Each determination was performed in triplicate and repeated at least three times.

\subsubsection{Radical Scavenging Activity}

The anti-radical activity of BW was determined using the stable 1,1-diphenyl-2-picrylhydrazyl radical (DPPH') (Sigma, Milan, Italy) and the procedure previously described [28]. In its free radical form, $\mathrm{DPPH}^{*}$ has an absorption band at $517 \mathrm{~nm}$ which disappears upon reduction by an anti-radical compound. Absorbance at $517 \mathrm{~nm}$ was measured on a Shimadzu UV-1601 UV-vis spectrophotometer 20 min after starting the reaction. The $\mathrm{DPPH}^{*}$ concentration in the reaction medium was calculated from a calibration curve analyzed by linear regression. Each determination was carried out in triplicate and repeated at least three times. Results were expressed as $\mathrm{mg}$ of extract needed to scavenge 50 mmoles of initial DPPH concentration (SE 50). 


\subsection{3. $\beta$-Carotene Bleaching Test}

This assay was carried out according to the method of Aidi Wannes et al. [33] with some modifications. To prepare a stock solution of a $\beta$-carotene-linoleic acid mixture, $1 \mathrm{mg}$ of $\beta$-carotene (purity $\geq 97 \%$; Sigma) was dissolved in $10 \mathrm{~mL}$ of chloroform (HPLC grade, purity $\geq 97 \%$; Carlo Erba), and then $5 \mathrm{~mL}$ of this solution were added to $40 \mu \mathrm{L}$ of linoleic acid (purity $\geq 99 \%$; Sigma) and $400 \mu \mathrm{L}$ of Tween 40 (Sigma). Chloroform was removed using a rotary evaporator at $40{ }^{\circ} \mathrm{C}$ for 5 min and then $100 \mathrm{~mL}$ of distilled water were slowly added to the residue to form an emulsion. Five milliliters of the emulsion were added to $200 \mu \mathrm{L}$ of methanol/water (2/1) solution containing the extract to be studied at different concentrations $(0.25-10 \mathrm{mg} / \mathrm{mL})$; the same volume of the solvent alone (methanol/water, $2 / 1)$ was used in control samples. The absorbance was immediately measured $(\mathrm{t}=0 \mathrm{~min})$ at $470 \mathrm{~nm}$ against a blank, consisting of an emulsion without $\beta$-carotene. The sample was then placed in a water bath at $50{ }^{\circ} \mathrm{C}$ and the oxidation of the emulsion was monitored by measuring absorbance at $470 \mathrm{~nm} 120 \mathrm{~min}$ after the beginning of the reaction. The percentage of inhibition respect to the control was calculated as follows:

$$
\left.\% \text { of inhibition }=\left[\left(\mathrm{A}_{\mathrm{t}}-\mathrm{C}_{\mathrm{t}}\right) / \mathrm{C}_{0}-\mathrm{C}_{\mathrm{t}}\right]\right] \times 100
$$

where $A_{t}$ and $C_{t}$ are the absorbances measured for the tested sample and the control sample, respectively, at $\mathrm{t}=120 \mathrm{~min}$, and $\mathrm{C}_{0}$ is the absorbance value for the control sample measured at $\mathrm{t}=0$ min. Each determination was carried out in triplicate and repeated at least three times. Results were expressed as $\mathrm{mg} / \mathrm{mL}$ of extract needed to inhibit $\beta$-carotene bleaching by $50 \%\left(\mathrm{IC}_{50}\right)$.

\subsubsection{Reducing Power Test}

The reducing power of the blanch water extract was determined according to the method of Oyaizu [34] as amended by Martorana et al. [11]. In this assay, the yellow colour of the test solution turns into green/blue whose intensity depends on the reducing power of the antioxidants present in the solution, which cause the reduction of the $\mathrm{Fe}^{3+}$ /ferricyanide complex to the ferrous form; therefore, $\mathrm{Fe}^{2+}$ can be monitored by the measurement of the absorbance at $700 \mathrm{~nm}$.

Briefly, $200 \mu \mathrm{L}$ of methanol/water (2/1) solutions containing BW extract at a concentration able to give a final reading between 0.3 and $0.7 \mathrm{AU}$ were mixed with $0.5 \mathrm{~mL}$ of $0.2 \mathrm{M}$ sodium phosphate buffer ( $\mathrm{pH}$ 6.6) (sodium phosphate dibasic heptahydrate $\left(\mathrm{Na}_{2} \mathrm{HPO}_{4}\right.$, ACS Reagent grade, purity 98\%-102\%; Sigma), sodium phosphate monobasic monohydrate $\left(\mathrm{NaH}_{2} \mathrm{PO}_{4} \cdot \mathrm{H}_{2} \mathrm{O}\right.$, ACS Reagent grade, purity $98 \%-102 \%$; Sigma) and $0.5 \mathrm{~mL}$ of $1 \% \mathrm{~K}_{3} \mathrm{Fe}(\mathrm{CN})_{6}$ (purity $99 \%$; Sigma), and then incubated in a water bath at $50{ }^{\circ} \mathrm{C}$ for $20 \mathrm{~min} .0 .5 \mathrm{~mL}$ of $10 \%$ trichloroacetic acid (TCA, Sigma) was then added to the mixture which was centrifuged at $8,300 \times g$ for $10 \mathrm{~min}$. The supernatant $(0.5 \mathrm{~mL})$ was mixed with $0.5 \mathrm{~mL}$ of distilled water and $0.1 \mathrm{~mL}$ of $0.1 \%$ ferric chloride solution (purity $\geq 99.99 \%$; Sigma). The intensity of the blue-green colour was measured at $700 \mathrm{~nm}$. Each determination was performed in triplicate and repeated at least three times.

Under the same conditions described above, different concentrations of ascorbic acid (AA, Sigma) were tested in order to measure their reducing power. A calibration curve of Prussian Blue (Sigma) (concentration range 10-150 $\mu \mathrm{M}$ ), dissolved in a mixture of water, phosphate buffer, TCA and 
methanol (71.48/13.37/13.37/1.78), was used to calculate the number of nmoles of Prussian Blue formed by the reaction between $\mathrm{AA}$ and $\mathrm{Fe}^{3+}$. The number of $\mathrm{Fe}^{2+}$ nmoles was calculated as follows:

$$
\text { nmoles } \mathrm{Fe}^{2+}=\frac{55.8 \times\left(\frac{A_{c}-0.0083}{0.0053}\right)}{329.196} \times 3.74
$$

where 55.8 is the atomic weight of iron; $\mathrm{A}_{\mathrm{C}}$ is the absorbance at $700 \mathrm{~nm}$ of the reaction mixture containing AA; 0.0083 and 0.0053 are intercept and slope values of Prussian Blue equation, respectively; 329.196 is the molecular weight of Prussian Blue; 3.74 is the dilution factor.

Thus, plotting the number of AA nmoles employed $v s$ the number of formed $\mathrm{Fe}^{2+}$ nmoles, a straight line was obtained, which was used to calculate the reducing power of the tested extract. The results were expressed as mmoles of AA equivalents (AAE) per gram of extract.

\subsubsection{UV-induced Peroxidation in Liposomal Membranes (UV-IP Test)}

The protective effect of the BW extract against UVC-induced peroxidation was evaluated on phosphatidylcholine (PC) multilamellar vesicles [35]. Briefly, a volume (950 $\mu \mathrm{L})$ of liposome suspension containing $10 \mathrm{mg} / \mathrm{mL}$ of PC (from egg yolk type XI-e; Sigma) (in a glass flask with a $3 \mathrm{~cm}^{3}$ exposure surface area) was exposed to UV radiation from a $15 \mathrm{~W}$ Philips germicidal lamp $(254 \mathrm{~nm}$ ) for $1.5 \mathrm{~h}$. Exposure was given at $10 \mathrm{~cm}$ from the lamp, and the experiment was carried out at $37{ }^{\circ} \mathrm{C}$. Fifty microliters of a methanol/water (2/1) mixture containing the extract to be tested at different concentrations were added to the system; an equal volume $(50 \mu \mathrm{L})$ of the vehicle alone was added to control tubes. Malondialdehyde (MDA) concentration formed in the mixtures following UV-C irradiation was measured using a colorimetric assay. In this assay, N-methyl-2-phenylindole (purity 99\%; Sigma) reacts with MDA to give a stable chromophore with a $\lambda_{\max }$ at $586 \mathrm{~nm}$. To calculate the amount of MDA formed in the samples, a calibration curve was prepared by submitting methanolic solutions of 1,1,3,3-tetramethoxypropan (Sigma), at different concentrations, to the same procedures described above. All determinations were carried out in triplicate and repeated at least three times. The results were expressed as concentration of the extract needed to inhibit MDA formation by $50 \%$ (IC50) with respect to the control.

\subsection{In Vivo Study on Photoprotective Activity}

\subsubsection{Preparation of Topic Formulations}

To evaluate the photoprotective effect of the extract under investigation in vivo, we used a formulation containing either $2 \%$ BW extract or $2 \%$ tocopheryl acetate (TOC) (as a reference ingredient). The composition of each formulation is reported in Table 5. Each oil/water (O/W) emulsion was prepared by slowly adding the aqueous phase to the oily phase and by blending the surfactants under continuous agitation, at $70{ }^{\circ} \mathrm{C}$. The mixture was stirred until cool, forming the emulsion formulation. Moreover, a formulation without active ingredients was used in the study (blank). PPG-15 stearyl ether, steareth 2, steareth 21, isohexadecane/PPG-15 stearyl ether; cetylstearylic acid; xantan gum; undebenzophenon were bought from Croda (Milan, Italy); stearic acid was purchased from Fluka. 
Table 5. Composition of the topical formulations containing the Blanch Water (BW) extract or tocopheryl acetate as reference substance (TOC), or without active ingredients (Blank).

\begin{tabular}{|c|c|c|c|}
\hline Formulation & Oil phase & Acqueous phase & $\begin{array}{c}\text { Surfactants and } \\
\text { structurizing agents }\end{array}$ \\
\hline Blank & $\begin{array}{l}\text { PPG-15 stearyl ether }(8 \mathrm{~g}) \\
\text { isohexadecane } \\
\text { stearyl ether }(4 \mathrm{~g})\end{array}$ & Distilled water (76.7 g) & $\begin{array}{c}\text { Steareth } 2(3.5 \mathrm{~g}) \\
\text { Steareth } 21(2.5 \mathrm{~g}) \\
\text { Stearic acid }(2.5 \mathrm{~g}) \\
\text { Cetylstearylic acid }(2.1 \mathrm{~g}) \\
\text { Xantan gum }(0.3 \mathrm{~g}) \\
\text { Undebenzophenone }(0.4 \mathrm{~g})\end{array}$ \\
\hline TOC & $\begin{array}{l}\text { PPG-15 stearyl ether }(7 \mathrm{~g}) \text {; } \\
\text { isohexadecane } \backslash \text { PPG-15 } \\
\text { stearyl ether }(3 \mathrm{~g}) \\
\text { tocopheryl acetate }(2 \mathrm{~g})\end{array}$ & Distilled water (76.7 g) & $\begin{array}{c}\text { Steareth } 2(3.5 \mathrm{~g}) \\
\text { Steareth } 21(2.5 \mathrm{~g}) \\
\text { Stearic acid }(2.5 \mathrm{~g}) \\
\text { Cetylstearylic acid }(2.1 \mathrm{~g}) \\
\text { Xantan gum }(0.3 \mathrm{~g}) \\
\text { Undebenzophenone }(0.4 \mathrm{~g})\end{array}$ \\
\hline BW & $\begin{array}{l}\text { PPG-15 stearyl ether }(8 \mathrm{~g}) \\
\text { isohexadecane } \\
\text { stearyl ether }(4 \mathrm{~g})\end{array}$ & $\begin{array}{c}\text { Distilled water (74.7 g) } \\
\text { Blanch water extract }(2 \mathrm{~g})\end{array}$ & $\begin{array}{c}\text { Steareth } 2(3.5 \mathrm{~g}) \\
\text { Steareth } 21(2.5 \mathrm{~g}) \\
\text { Stearic acid }(2.5 \mathrm{~g}) \\
\text { Cetylstearylic acid }(2.1 \mathrm{~g}) \\
\text { Xantan gum }(0.3 \mathrm{~g}) \\
\text { Undebenzophenone }(0.4 \mathrm{~g})\end{array}$ \\
\hline
\end{tabular}

\subsubsection{Instruments}

Skin erythema was induced by UV-B irradiation using a UVM-57 ultraviolet lamp (UVP, San Gabriel, CA, USA). This source emits radiation in the range of 290-320 nm with an output peak at $302 \mathrm{~nm}$. The flux rate measured at the skin surface was $0.80 \mathrm{~mW} \mathrm{~cm}^{-2}$. For each subject the minimal erythema dose (MED) was determined and an irradiation dose corresponding to double the MED was used throughout the study. UV-B-induced skin erythema was monitored by using a reflectance visible spectrophotomer X-Rite model 968 (X Rite Inc., Grandville, MI, USA), having $0^{\circ}$ illumination and $45^{\circ}$ viewing angle, calibrated and controlled as previously reported [27]. Reflectance spectra were obtained over the wavelength range 400-700 $\mathrm{nm}$ using illuminant $\mathrm{C}$ and $2^{\circ}$ standard observer.

\subsubsection{Subjects}

In vivo experiments were performed on twelve healthy volunteers of skin types II and III, aged 25-35 years. The subjects were recruited after medical screening which included a health questionnaire and physical examination of the application sites. Subjects exhibiting features which might interfere with the evaluation, such as sunburn, skin lesions or abnormal sensitivity to sunlight, or taking medication at the time of the study, were excluded from the study. The volunteers were fully informed about the nature of the study, and about the products and procedures involved, and gave their written consent. Each subject was rested for $15 \mathrm{~min}$ before the experiments and room conditions were 
set at $22 \pm 2{ }^{\circ} \mathrm{C}$ and $40 \%-50 \%$ relative humidity. Two research assistants were responsible for subject recruitment and data collection.

\subsubsection{Protocol}

For each subject recruited in the experiment, eight sites in the ventral surface of the forearm were defined using a circular template $\left(1 \mathrm{~cm}^{2}\right)$ and demarcated with permanent ink. Baseline skin assessment was performed by reflectance spectrophotometry in all sites. Each site was exposed to UV-B irradiation, after which $200 \mathrm{mg}$ of each formulation (containing either BW or TOC, or the blank) were spread uniformly on the sites by means of a solid glass rod. For each forearm, two of the ten sites were used as control (no drug treatment). Afterwards, each skin site was occluded for $3 \mathrm{~h}$, using Hill Top chambers (Hill Top Research, Inc., Cincinnati, OH, USA), to prevent any loss of the material from the skin surface. After the occlusion period the chambers were removed and the skin surfaces were washed to remove the formulation and allowed to dry for $15 \mathrm{~min}$, after which the induced erythema was monitored for $58 \mathrm{~h}$ by reflectance spectrophotometry. Since erythema is due to an increment of blood supply in the subpapillary plexus of the skin, erythema index (E.I.) values were calculated by subtracting the logarithm of inverse reflectance $(\log 1 / \mathrm{R})$ values of $510 \mathrm{~nm}$ and $610 \mathrm{~nm}$ (mainly due to melanin absorption), from the sum of $\log 1 / \mathrm{R}$ values of 540, 560 and $580 \mathrm{~nm}$, which represents the wavelengths of hemoglobin absorption peaks (Equation 3) [27]:

$$
\text { E.I. }=100\left[\log \frac{1}{R_{560}}+1.5\left(\log \frac{1}{R_{540}}+\log \frac{1}{R_{580}}\right)-2\left(\log \frac{1}{R_{510}}+\log \frac{1}{R_{610}}\right)\right]
$$

To evaluate the time course of skin erythema, E.I. baseline values (before UV-B irradiation) were subtracted from the E.I. values obtained after UV-B exposure at each time point, to calculate $\Delta$ E.I. values. For each site, $\Delta$ E.I. was plotted versus time and the area under the curve (AUC) was computed using the trapezoidal rule to obtain AUC0-58, a dimensionless index directly related to the degree of skin erythema. To better compare the efficacy of the tested formulations, the percentage inhibition of UV-B skin erythema (PIE) was calculated from formulation AUC0-58 values using the equation (Equation 4):

$$
\% \text { inhibition }(P I E)=\frac{A U C_{(C)}-A U C_{(T)}}{A U C_{(C)}} \times 100
$$

where $\mathrm{AUC}_{(\mathrm{C})}$ is the area under the response-time curve of the sites no treated (control) and $\mathrm{AUC}_{(\mathrm{T})}$ is the area under the response-time curve of the sites treated with the tested formulation. Statistical analysis of AUC values, expressed as means and standard deviations, was performed using unpaired Student's t-test; $\mathrm{p}<0.05$ was considered to be significant.

\section{Conclusions}

Through our results we have demonstrated that blanch water, a byproduct of the almond processing industry, still contains high-value compounds which can be further utilized in the nutraceutical and pharmaceutical industries. A range of antioxidant tests has clearly demonstrated the radical scavenging capacity of blanch water and its potential use in conditions where an overproduction of free radicals 
occurs. The photoprotective effect of blanch water demonstrated in vivo has clearly highlighted an effect against photooxidative damage.

\section{Acknowledgments}

This research was funded by the University of Messina and the Almond Board of California.

\section{Conflicts of Interest}

The authors declare no conflict of interest.

\section{References}

1. Cohen, A.E.; Johnston, C.S. Almond ingestion at mealtime reduces postprandial glycemia and chronic ingestion reduces haemoglobin A1c in individuals with well-controlled type 2 diabetes mellitus. Metabolism 2011, 60, 1312-1317.

2. Li, S.C.; Liu, Y.H.; Liu, J.F.; Chang, W.H.; Chen, C.M.; Chen, C.Y. Almond consumption improved glycemic control and lipid profiles in patients with type 2 diabetes mellitus. Metabolism 2011, 60, 474-479.

3. Haider, S.; Batool, Z.; Haleem, D.J. Nootropic and hyphofagic effects following long term intake of almonds (Prunus amygdalus) in rats. Nutr. Hosp. 2012, 27, 2109-2115.

4. Food Labeling: Health Claims: Nuts and Heart Disease; Federal Register Docket number 02P-0505; U.S. Food and Drug Administration: Washington, DC, USA, 2003.

5. Mandalari, G.; Tomaino, A.; Arcoraci, T.; Martorana, M.; Lo Turco, V.; Cacciola, F.; Rich, G.T., Bisignano, C.; Saija, A.; Dugo, P.; et al. Characterization of polyphenols, lipids and dietary fibre from skins of almonds (Amygdalus communis L.). J. Food Comp. Anal. 2010, 23, 166-174.

6. Milbury, P.E.; Chen, C.-H.; Dolnikowski, G.G.; Blumberg, J.B. Determination of flavonoids and phenolics and their distribution in almonds. J. Agric. Food Chem. 2006, 54, 5027-5033.

7. Mandalari, G.; Tomaino, A.; Rich, G.T.; Lo Curto, R.; Arcoraci, T.; Martorana, M.; Bisignano, C.; Saija, A.; Parker, M.L.; Waldron, K.W.; et al. Polyphenol and nutrient release from skin of almonds during simulated human digestion. Food Chem. 2010, 122, 1083-1088.

8. Grasser, L.A.; Fadel, J.O.; Garnett, I.; DePeters, E.J. Quantity and economic importance of nine selected by-products. J. Dairy Sci. 1995, 78, 962-971.

9. Gonzáles, J.F.; Gañán, J.; Ramiro, A.; Gonzáles-García, C.M.; Encinar, J.M.; Sabio, E.; Román, S. Almond residues gasification plant for generation of electric power. Preliminary study. Fuel Proc. Technol. 2006, 87, 149-155.

10. Adhami, V.M.; Syed, D.N.; Khan, N.; Afaq, F. Phytochemicals for prevention of solar ultraviolet radiation-induced damage. Photochem. Photobiol. 2008, 84, 489-500.

11. Martorana, M.; Arcoraci, T.; Rizza, L.; Cristani, M.; Bonina, F.; Saija, A.; Trombetta, D.; Tomaino, A. In vitro antioxidant and in vivo photoprotective effect of pistachio (Pistacia vera L., variety Bronte) seed and skin extracts. Fitoterapia 2013, 85, 41-48. 
12. Saija, A.; Tomaino, A.; Trombetta, D.; de Pasquale, A.; Uccella, N.; Barbuzzi, T.; Paolino D.; Bonina F. In vitro and in vivo evaluation of caffeic and ferulic acid sas topical photoprotective agents. Int. J. Pharm. 2000, 199, 39-47.

13. Bonina P.; Saija, A.; Tomaino, A.; Lo Cascio, R.; Rapisarda, P.; Dederen, J.C. In vitro antioxidant activity and in vivo photoprotective effect of a red orange extract. Int. J. Cosmet. Sci. 1998, 20, 331-342.

14. Montenegro, L.; Bonina, F.; Dederen, J.C. In vivo protective effect of $\beta$-bis-(carboxyethyl)germanium sesquioxide. J. Soc. Cosmet. Chem. 1997, 47, 307-313.

15. Bonina, F.; Puglia, C.; Tomaino, A.; Saija, A.; Mulinacci, N.; Romani, A.; Vincieri, F.F. In vitro antioxidant and in vivo photoprotective effect of three lyophilized extracts of Sedum telephium L. leaves. J. Pharm. Pharmacol. 2000, 52, 1279-1285.

16. Bolling, B.W.; Chen, C.Y.; McKay, D.L.; Blumberg, J.B. Tree nut phytochemicals: composition, antioxidant capacity, bioactivity, impact factors. A systematic review of almonds, Brazils, cashews, hazelnuts, macadamias, pecans, pine nuts, pistachios and walnuts. Nutr. Res. Rev. 2011, 24, 244-275.

17. Tatsuno, T.; Jinno, M.; Arima, Y.; Kawabata, T.; Hasegawa, T.; Yahagi, N.; Takano, F.; Ohta, T. Anti-inflammatory and anti-melanogenic proanthocyanidin oligomers from peanut skin. Biol. Pharm. Bull. 2012, 35, 909-916.

18. Dell'Agli, M.; Busciala, A.; Bosisio, E. Vascular effects of wine polyphenols. Cardiovasc. Res. 2004, 63, 593-602.

19. Bagchi, D.; Bagchi, M.; Stohs, S.J. Free radicals and grape seed proanthocyanidin extract: Importance in human health and disease prevention. Toxicology 2000, 148, 187-197.

20. Pérez-Jiménez, J.; Lluís Torres, J. Analysis of proanthocyanidins in almond blanch water by HPLC-ESI-QqQ-MS/MS and MALDI-TOF/TOF MS. Food Res. Int. 2012, 49, 798-806.

21. Richelle, M.; Tavazzi, I.; Offord, E. Comparison of the antioxidant activity of commonly consumed polyphenolic beverages (coffee, cocoa and tea) prepared per cup serving. J. Agric. Food Chem. 2001, 49, 3438-3442.

22. Huang, D.; Ou, B.; Prior, R.L. The chemistry behind antioxidant capacity assays. J. Agric. Food Chem. 2005, 53, 1841-1856.

23. Huang, B.; Zhu, L.; Liu, S.; Li, D.; Chen, Y.X.; Ma, B.X.; Wang, Y.W. In vitro and in vivo evaluation of inhibition activity of lotus (Nelumbo nucifera Gaertn.) leaves against ultraviolet B-induced phototoxicity. J. Photochem. Photobiol. B 2013, 121, 1-5.

24. Kim, S.H.; Jung, E.Y.; Kang, D.H., Chang, U.J.; Hong, Y.H.; Suh, H.J. Physical stability, antioxidative properties, and photoprotective effects of a functionalized formulation containing black garlic extract. J. Photochem. Photobiol. B 2012, 117, 104-110.

25. Meinke, M.C.; Schanzer, S.; Haag, S.F.; Casetti F.; Muller, M.L.; Wolfle, U.; Kleemann, A.; Lademann, J.; Schempp, C.M. In vivo photoprotective and anti-inflammatory effect of hyperforin is associated with high antioxidant activity in vitro and ex vivo. Eur. J. Pharm. Biopharm. 2012, 81, 346-350.

26. Cimino, F.; Sulfaro, V.; Trombetta, D.; Saija, A.; Tomaino, A. Radical-scavenging capacity of several Italian red wines. Food Chem. 2007, 103, 75-81. 
27. Bonina, F.; Puglia, C.; Ventura, D.; Aquino, R.; Tortora, S.; Sacchi, A.; Saija, A.; Tomaino, A.; Pellegrino, M.L.; de Capraris, P. In vitro antioxidant and in vivo photoprotective effects of a lyophilized extract of Capparis spinosa L buds. J. Cosmet. Sci. 2002, 53, 321-335.

28. Aquino, R.; Morelli, S.; Tomaino, A.; Pellegrino, M.L.; Saija, A.; Grumetto, L.; Puglia, C.; Ventura, D.; Bonina, F. Antioxidant and photoprotective activity of a crude extract of Culcitium reflexum H.B.K. leaves and their major flavonoids. J. Ethnopharmacol. 2002, 79, 183-191.

29. Spagna, G.; Tomaino, A.; Cimino, F.; Barbagallo, R.N.; Ventura, D.; Bonina, F.; Saija, A. Chemical analysis and photoprotective effect of an extract of wine from Jacquez grapes. J. Sci. Food Agric. 2002, 82, 1867-1874.

30. Di Stefano, Cravero, M.R.; Gentilini, M. Methods for the study of wine polyphenols. L'Enotecnico 1989, 5, 83-89.

31. Margheri, G.; Falcieri, E. Importanza dell'evoluzione delle sostanze polifenoliche nei vini rossi di qualità durante l'invecchiamento. Vini d'Italia 1972, 14, 81-84.

32. Tomaino, A.; Cristani, M.; Cimino, F.; Speciale, A.; Trombetta, D.; Bonina, F.; Saija, A. In vitro protective effect of a Jacquez grapes wine extract on UV-B induced skin damage. Toxicol. In Vitro 2006, 20, 1395-1402.

33. Aidi Wannes, W.; Mhamdi, B.; Sriti, J.; Ben Jemia, M.; Ouchikh, O.; Hamdaoui, G.; Kchouk, M.E.; Marzouk, B. Antioxidant activities of the essential oils and methanol extracts from myrtle (Myrtus communis var. italica L.) leaf, stem and flower. Food Chem. Toxicol. 2010, 48, 1362-1370.

34. Oyaizu, M. Studies on product of browning reaction prepared from glucosamine. Jpn. J. Nutr. 1986, 44, 307-315.

35. Saija, A.; Tomaino, A.; Trombetta, D.; Pellegrino, M.L.; Tita, B.; Caruso, S.; Castelli, F. Interaction of melatonin with model membranes and possible implications in its photoprotective activity. Eur. J. Pharm. Biopharm. 2002, 53, 209-215.

Sample Availability: Samples of blanch water are available from the authors.

(C) 2013 by the authors; licensee MDPI, Basel, Switzerland. This article is an open access article distributed under the terms and conditions of the Creative Commons Attribution license (http://creativecommons.org/licenses/by/3.0/). 